\title{
Lego, Handcraft, and Costumed Zombies: What Zombies do on Flickr
}

\author{
TREVOR OWENS \\ University of Maryland
}

Abstract: The popular photo-sharing site Flickr contains about half a million images associated with the term zombie. What can we learn about our monsters and ourselves by exploring this vernacular collection of depictions? This essay explores this and related questions by treating the first 300 results of a search on Flickr as a single cultural text. In exploring what Zombies might mean on Flickr, this study suggests how existing approaches to the study of cultural texts can be applied to the algorithmically generated presentation of vernacular images. The results document how Flickr facilitates and sustains a vernacular web of participatory media.

In June of 2010 the term zombie was associated with 477,890 images on the photosharing site Flickr. The much older and arguably more popular form of living dead, the vampire, was associated with less than half that amount: 222,739 images. Werewolves returned a measly 24,844 images. As far as Flickr community members are concerned, zombies are clearly the most documented of the monster movie's stock characters. While zombies win two to one in terms of Flickr photos, the trends are reversed in what Google users search for. As illustrated in the chart from Google trends below, Google searchers consistently seek information about vampires at just about twice the frequency that they search for zombies.

Interest over time

News headlines $\square$ Forecast

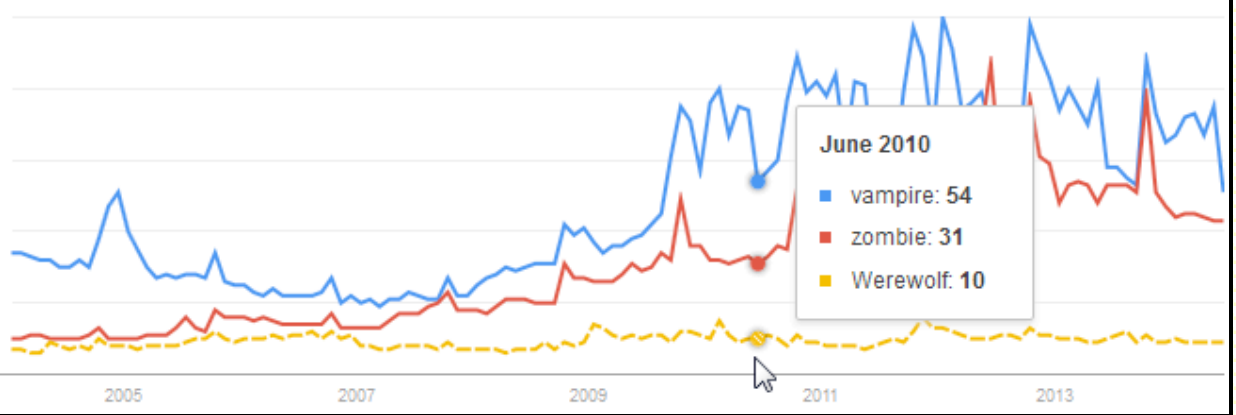


An even more exaggerated difference emerges in looking at usage of the term's vampire and zombie in the massive corpus of Google books over time. The image below shows just how much more frequently the term vampire appears in English language books than zombie over the last 200 years. In terms of usage in books, vampires have had, and have only continued to increase, their substantial lead on zombies. While the term vampire has been around for a good while longer the term zombie has never really caught up.

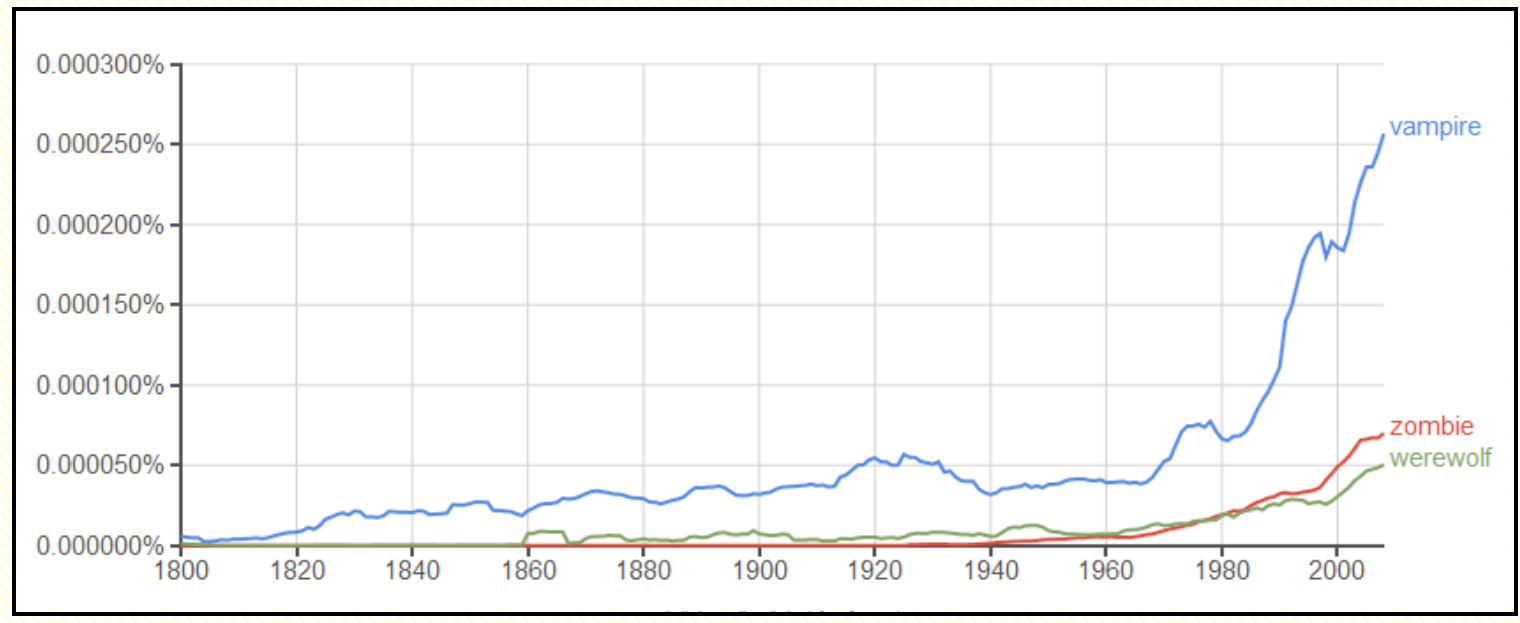

What is it about zombies that reverses the trends in searches and publishing? Why are zombies so much more popular in association with photographs people create and share on Flickr? Zombies and vampires aside, the differences here open up and suggest a way of studying culture and its use. How are people making use of and deploying cultural tropes in the photos they share on Flickr?

There is a solid tradition of studying mass media representations of these monsters. The early twentieth century Haitian zombie found in White Zombie (1932) offers opportunities to explore issues of labor and race; Romero's Night of the Living Dead (1968) presents a site to explore issues of consumption; and films like 28 Days Later (2002) provides insight into anxieties over science, viruses, and infection paranoia. To what extent does the presence and popularity of the zombie in Flickr photos tell us about the idea of the zombie in contemporary culture? What can we learn about our monsters through this repository of vernacular expressions? 
Flickr's public repository of zombie-associated images provides a unique vantage point for examining a concept like the zombie. In this essay, I explore what happens if we think about the results of a search on Flickr as constituting a single cultural text. In exploring what zombies might mean on Flickr I offer a case study in how existing approaches to the study of cultural texts might be applied to the algorithmically generated presentation of vernacular photos on Flickr.

What we learn about zombies on Flickr tells us a little bit about what zombies mean and do, but far more about how DIY culture works in a space like Flickr. Flickr users have taken the metaphor and used it in very playful ways. The tensions between these different uses of zombies offer insight into the proliferation of the idea of the zombie. The images range from the grotesque and horrific photos of costumed individuals missing their jaws, dripping with blood and gore to "Zombie Apocalypse" Lego sets to what could best be described as "cute" hand-stitched zombie purses. In the following analysis I suggest that on Flickr the zombie is being used to express one's creativity. Specifically, that the juxtaposition of the cute and the disturbing, and other visually salient characteristics of the zombie, provide individuals with an easy-to-use trope to deploy in the creative projects they document and share on Flickr. What is it about this "medium" or its salient characteristics that requires or encourages the use of an easily-deployed trope?

\section{The Rise of Flickr}

Launched in 2004, Flickr has rapidly become one of the most popular photo sharing websites. Originally created by a Vancouver-based startup called Ludicorp, it was purchased by Yahoo in 2005. As with most social networking sites, individual users create profiles, add friends, and join groups. Members can upload photos and share them publicly or privately with selected users. The site offers all users a large amount of free storage, and much more for a fee. Users can upload an unlimited number of photos and videos. Members can include descriptive information about 
their photos and a set of tags-or keywords-that describe and link their photos to the work of other users.

With more than six billion photos, Flickr boasts one of the largest repositories of images. Various communities and organizations use it as a platform to share personal and professional photos. For perspective, the web ranking service Alexa.com ranks Flickr as the sixty-third most trafficked site in the US. Flickr is both a place to explore creative production and a popular place for individuals to find example images, images to use on their desktop backgrounds, or images to use in presentations and on websites. In this respect, a study of images on Flickr is both a study of creative productions and a study of the contents of a popular image repository used by a wide audience. Furthermore, few other photo-sharing sites offer the same kind of extensive ability to search and explore their content. Flickr should thus be analyzed as both a corpus of individual creations and as an evergrowing "text" with millions of writers and readers, constructed from the connections participants establish.

\section{Zombies in Mass, Popular \& Vernacular Culture}

In Understanding Popular Culture (1989), cultural studies scholar John Fiske suggests that cultural commodities must meet a set of seemingly contradictory criteria. Cultural commodities must serve both the centralizing, homogenizing needs of the economy and the opposing needs of individuals to "evade or resist its disciplinary efforts, fracture its homogeneity and coherence, raid or poach upon its terrain" (28). For Fiske, this contradiction is resolved in the distinction between popular and mass culture. Mass culture represents the homogenizing force and popular culture represents the way individuals use elements of mass culture in their daily lives. Here Fiske draws on De Certeau's notion of "resistance" as the core activity of popular culture. In this framework, popular culture is the arena in which individuals resist the homogenizing force through a range of behaviors that change and alter cultural commodities. The distinction is best understood in one of Fiske's 
examples. Blue jeans are a cultural commodity, mass-produced with a huge consumer base. This makes them products of mass culture. Some individuals who buy these jeans will rip, tie-dye, or otherwise alter them. In altering their blue jeans, individuals create a popular culture by resisting the dominant, homogenized commodity the original mass-produced blue jeans represent.

While the idea of the zombie is much less of a physical commodity than blue jeans, the juxtaposition between popular and mass culture is a helpful framework for thinking about the different ways the zombie is deployed. For example, much scholarship on zombies concentrates on how they appear in particular films, books, or, more recently, video games. Criticism tends to focus around a particular set of texts, often those considered the most culturally or aesthetically significant. By contrast, the approach undertaken in this essay is to examine the way large groups of individuals are manipulating, incorporating, and altering the figure of the zombie in their daily life. By documenting how individuals are using the zombie metaphor in their photos on Flickr, this essay tries to gain insight into the idea of the zombie as transformed by participatory culture and folksonomic data. The kinds of cultural interactions on Flickr can also be understood as "participatory culture" in which "relatively low barriers to artistic expression" and "strong support for creating and sharing one's creations" are hallmarks of online interaction (Jenkins et al. 2006, 3). Still, Fiske's popular/mass culture dichotomy is useful for analytical purposes as it adds clarity to the way average individuals are deploying (and I will suggest, playing with) the cultural toolkit that emerge from the zombie imagery as seen in mass culture. To this end, sites like Flickr offer access to the vernacular web (Howard 2008), where everyday people create and share their ideas and notions through the infrastructure provided by companies like Flickr.

\section{Reading the Flickr Zombies Text}

To get a sense of the ways the idea of the zombie was being used on Flickr, I examined the 300 photos which Flickr's algorithm deemed most "relevant." After 
building the corpus I engaged in a process of direct analysis to explore the "content and character" of the images (Collier 2001,39) Before moving into analysis, I will briefly discuss how Flickr's search functions work and why the criterion of relevance was chosen as the basis for generating this corpus.

Flickr's search returns all of the images that include the search term in tags, text, and image description. Thus, 477,890 images had the term zombie in the text accompanying the images. Flickr provides users with three different options for sorting search results: by most recently uploaded, by (what Flickr deems) the most interesting, or by the most relevant images. Flickr has not publicly described the details of the sorting algorithms, but the general differences between these sorting behaviors are widely known. Using the recent uploaded sorting parameter will simply organize the entire list in reverse chronological order. This is a convenient way to organize images, but is heavily affected by individual users. For example, at the time of writing, sorting according to recent uploads returned nearly fifty images by the same user who had uploaded a single batch of zombie-related photos. This sort mechanism does not take into account available community usage data such as views of the image, comments, notes, or frequency of being rated as a "favorite." By contrast, using the "interesting" sorting focuses almost entirely on use. Flickr determines if a photo is interesting by weighing views of the photo, number of comments on the photo, number of commentators, number of groups in which the photo appears, how often it has been added to a user's favorite images, and the length of time the image has been hosted on the site. This sorting mechanism privileges more professional photographs. Finally, sorting according to relevancy includes a mixture of community usage data while also privileging keywords in titles and the frequency of keyword appearance. Selecting a search by "relevance" serves three goals. First, it provides a more diverse mixture of amateur and professional photographs. Second, balancing more traditional search approaches, such as the location of a keyword in a title, with data on community activity ensures the resulting images are content relevant and relevant to the user community's 
interests. Third, and most importantly, relevance is the default sorting parameter. In other words, when anyone visits Flickr and types "zombie" into the search box they will receive images sorted by relevance.

Using the relevant sorting-parameter means that the corpus I generated is not a random selection of the images on Flickr. The analysis presented here does not attempt to generalize to the "average" kind of zombie images shared on Flickr. It is important to remember that these images are not simply representative of individual's productions; Flickr is fundamentally about sharing those productions. By relying on this algorithm the study is both an examination of these images and a study of the algorithm that is inextricably and intimately embedded in the structure of the site. The relevance algorithm is an example of what Lev Maonvich refers to as transcoding, where the ontology of the computer is projected "onto culture itself" (Manovich 2001, 223). The algorithm I used to generate this corpus is the algorithm that facilitates interaction with these images. It is the logic that dictates which images are seen and which kinds of images are viewed. Taking the images Flickr's algorithm deems most relevant provides for analysis of both the kinds of images participants are sharing and the kinds of things users will find if they search for the term zombie on the site.

After collecting the corpus of images into a database I worked through a process of thematic coding to identify trends surrounding the kinds of images people were sharing. After developing a set of codes, I then applied them to each image to establish the extent to which different trends emerge in the corpus. What follows is a reading of the "text" that Flickr created for anyone looking for zombies around the date I looked for them on Flickr. The author of this work can be thought of as the result of the distributed interplay between the creators of these photos, the algorithm that prioritizes them, and the social usage data that is used to power that algorithm. 


\section{9\% Literal Zombies}

With the exception of three photos, the images featured explicitly literal visual representations of zombies. There are people dressed up as zombies individually and at zombie walks, zombie toys, zombie cakes, Lego zombies, and zombie purses. While the obvious explanation may be that Flickr is an image-based site, the insistent focus on the literal visual zombie as taken from the cinematic tradition suggests that the visual aspect is the most culturally potent aspect of the creature. While the metaphoric implications of the zombie may be of primary interest to scholars, this sample of the way in which the general public deploys zombies suggests that the character of the zombie, and its visual cues, is of the utmost importance to Flickr community members and the various popular communities represented within.

It is important to remember that the sample of images used to conduct this study relied on Flickr's relevance algorithm. One possibility for explaining the prominence of these literal zombies is that the search algorithm privileges them, allowing the logic of the algorithm to shape the cultural exchange between individuals using Flickr. With that noted, it is also possible that a focus on literal zombies is a product of the low barrier to participation to sharing cultural productions on a site like Flickr. One could view differences, like this focus on literal zombies, as a manifestation of what folklorist Robert Glenn Howard refers to as the vernacular web of participatory media (2008). The algorithm and changes to barriers to participation work together to explain differences like this focus on literal images. While anyone can participate, only those whose participation is favored by the algorithm become networked and highly trafficked.

The exceptions to this understanding of the zombie are so few that they are worth documenting. "TV Nation Zombie kid" features a close-up of a child whose eyes have been replaced with the glimmering reflections of television static. "Learn to walk the line" shows a machine that turns vibrant and wild haired Lego minifigures into identical grey haired Lego minifigures. Finally, while "I studied too 
hard and became a zombie" does include a picture of a man dressed up as a zombie, it explicitly plays on the idea that the boredom and conformity of school turns students into a zombie. For good measure, this zombie has a \#2 pencil protruding from his head. While the remaining $99 \%$ of the images may also include larger metaphorical connotations, the user is confronted with the irreducibly visual manifestation of zombie. What follows is an analysis of the creative and variegated uses that individuals have found for the visual zombie trope.

\section{Zombie Mashups}

Zombie Hunter Autobot, Little Red Riding Hood Zombie, Geisha Ninja Zombie Killer, Zombie Christ, Happy Obama Zombie, Zombie Voltron, Zombie Cowgirl II, Zombie Palin, Zombies for Health Care Reform, Che in the Service of Zombie Fighters, Ninja and Zombie chill out, Gangsters VS Zombies: the titles of these Flickr photos speak directly to the contents of the photos and, more substantively, to the way Flickr members are mixing and mashing-up different cultural references. This mixture of familiar childhood cartoon characters such as Transformers and Red Riding Hood; political figures like Sarah Palin, Barack Obama, and Che Guevara; and other stock characters such as ninjas and gangsters is a common practice among Flickr users. Roughly a third of the images reflect a visual mix and match of characters and ideas. On Flickr the zombie is not a single entity, but serves as a visual filter through which genres, people, and objects are "zombified." There is infectiousness to the zombie itself as it cannibalizes and is cannibalized by popular culture.

An in-depth analysis of individual examples provides a context for developing a model of what Flickr users are doing with the zombie. Consider the image titled "Love is... accepting he's a Zombie." Its creator_Matn informs viewers that he created the image for "the Big Toy Hut LEGO Zombie Contest." The Big Toy Hut is a small boutique web-store that specializes in selling custom Lego minifigures to adult die-hard Lego fans. In the description of the photo _Matn tells visitors that 
the image is of "A kitchen, where a lovely housewife takes care of her zombie husband. Includes a sink and an oven with an extractor hood. The chairs are a design by mijasper on Brickshelf." It is clear that_Matn spent a significant amount of time designing the Lego diorama. The kitchen has a checkerboard tile floor and thoughtfully designed range, refrigerator, sink, cabinets, and table set. The zombie husband is wearing a suit and is seated at the table. On the table in front of him is a bowl with a Legoman's arm in it. His wife is seen holding a wine glass filled with a red substance on the table.

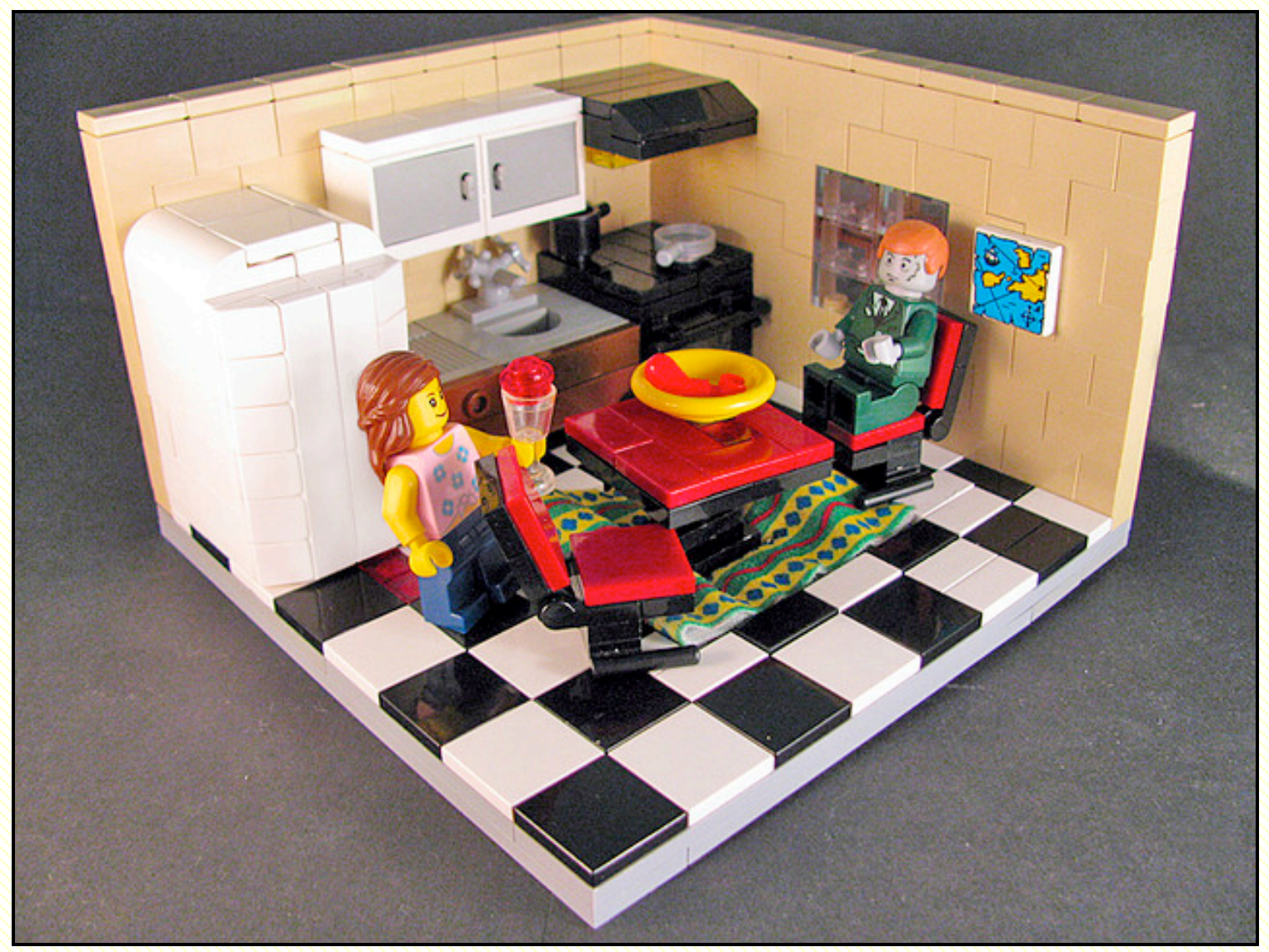

Love is.......accepting he's a zombie,_Matn, April 15, 2009, Shared with permission from the author http://www.flickr.com/photos/30479264@N06/3446389497/

There are several facets of this image that warrant consideration. First, the concept of the image begins with a play on a range of quotations about love. In 
particular, the image borrows its premise from the 1970s comic strip Love is... Much like _Matn's image, each single-frame Love is... strip shares an image of two individuals and additional text to complete the sentence. In this case,_Matn uses the idea of the zombie to play with a cliché about love. The painstaking detail of the kitchen adds to the humor of the image. By placing the monstrous figure of the zombie in this peaceful domestic scene and serving him a Legoman's arm, the joke works by the jarring contrast of the zombie eating human flesh in a comfortable, bourgeois kitchen. Beyond this punch line,_Matn's precise description of the details of the kitchen draws the viewer's attention away from the gory diegesis to focus on the way he built the sink, the oven, and the hood. _Matn diverts our attention away from the visual joke towards his technical mastery of Lego diorama design. The resulting discussion of the image in the comments provides additional insight into how other community members understand the image. The following is a selection of the comments. (NB: "vig" is short for "vignette.")

Commenter 1: Awesome vig! Great details on the kitchen and appliances. Good luck with the contest.

Commenter 2: Ha ha, excellent title, excellent vig (though a little cramped). I love the idea.

Commenter 3: Great scene! Nice to take a zombie theme to such an everyday level. I had not heard of the contest or Big Toy Hut before, but if I can think of something I might enter too...

Commenter 4: nicely done, i love all the details. great work!

Commenter 5: Nice vig. I'm really liking the oven, range, and hood. Looks great!

Commenter 6: Was this inspired by shaun of the dead? _Matn: Thanks! no it wasn't, haven't seen that movie. :)

Commenter 7: You should definitely go and watch it then ;-) Simon Pegg at his best.

Commenter 8: Hahah. Definitely thought of Shaun of the Dead, too, but this is brilliant in it's own right.

Commenter 9: Hi, I'm an admin for a group called LEGO Kitchen, and we'd love to have this added to the group!

Commenter 10: How did you make the sink?

Commenter 11: I LOVE the lil map on the wall!! My favourite part :) 
While one might think that the visual joke in the image would be the focus of attention, the comments are consistently oriented towards the details of the kitchen appliances. The discussion consists mostly of accolades for the details involved in _Matn's construction of kitchen appliances (cf. commenter 1, 2, and 4). Commenter 10 requests details on how_Matn constructed the sink. In short, the primary focus of the discussion is on the composition of this custom Lego set. Although commenter 3's statement "Nice to take the zombie theme to such an everyday level" offers praise for_Matn's clever concept, and the resulting discussion of Shaun of the Dead indicates that cultural readings are being performed, the remaining conversation indicates that the zombie is primarily a prop for this particular community of users to discuss technical issues surrounding custom-designed Lego vignettes. The way in which the users comment on _Matn's project is not an isolated phenomenon, yet before we examine some of the other appropriations of the zombie, it is important to explore why exactly a small boutique web-store hosted a zombie-related Lego competition in the first place.

\section{BrickCon and the Zombie ApocaFest}

More than 20\% (64/300) of the images Flickr deemed most relevant involve Lego and of those images, nearly all are associated with a Seattle event called Zombie ApocaFest, which occurred in conjunction with BrickCon 2008 and 2009. BrickCon is a Lego enthusiast convention. Images in this series generally show carefully constructed scenes and vignettes that borrow from apocalyptic zombie lore. For the event a range of Lego enthusiasts pooled together their sets to create a massive zombie ravaged cityscape.

Events like Zombie ApocaFest illustrate the intriguing ways that a site like Flickr, and the communities that use it to share photos, are engaging with more widespread mass cultural commodities. The 2008 Zombie ApocaFest was so successful as an enthusiast event that it attracted attention and sponsorship from 
Valve, the creators of the Left 4 Dead. On the Left 4 Dead blog, video game writer Eric Wolpaw describes the event as "a giant, bloody urban zombie apocalypse rendered entirely in Lego." Indeed, alongside the zombie-infested Lego sits a Left 4 Dead Lego billboard, on which the four characters from the original Left 4 Dead game appear as Lego mini-figures. In this case, the creators of Left 4 Dead, itself an important mass culture text about zombies, are engaging directly with an enthusiast community.

In this case, the zombie has been picked up as an occasion for the already vibrant BrickCon community to bend and subvert the existing sets of Lego pieces created to enable children to build and play with cityscapes. The images from Zombie Apocafest shared on Flickr document how these individuals have mixed horror and apocalyptic themes associated with zombies together with the bright Lego pieces, originally conceived of as a children's toy. The community of adults interested in Lego has resulted in a small industry catering to these desires. One of the other sponsors of Zombie Apocafest, BrickArms, is a small business, which since 2006 has been supplying Lego enthusiasts with "realistic looking, Lego-handcompatible guns and weaponry." For a dollar you can buy a sawed-off shotgun or, for fifty cents more, a high caliber sniper rifle for any of your Lego mini-figures.

In this case, the Lego fan community has appropriated the zombie as a clever way to use the provided Lego pieces to tell a very different kind of story. In the case of these Lego zombie vignettes the community members have taken the architecture of conventional town and home life afforded by traditional Lego sets and inverted it to tell horror stories. With only minor changes to the pieces, in some cases replacing the heads of normal Lego town folk mini-figures with zombie Lego heads, the participants have transformed the story a Lego can tell. Instead of the pleasure of building a world, they are engaging in the somewhat paradoxical endeavor of building a world in the process of being destroyed.

\section{DIY Zombies}

_Matn's playful manipulation of the zombie in his Lego vignette is similar to 
how other Flickr community members have made use of the zombie. Within the corpus of images there are two homemade zombie stuffed animals, " $\vee$ Cat Zombie Plushie - Katzenzombie $\bullet$ " and another called "Zombie Voodoo LaRue." There are also four images of zombie cakes, one of which is a cake made to look like a brain being served by a zombie and the other three of which are cakes made to look like zombies. In the case of the zombie stuffed animals, the creators have mixed the cute with the idea of the zombie.

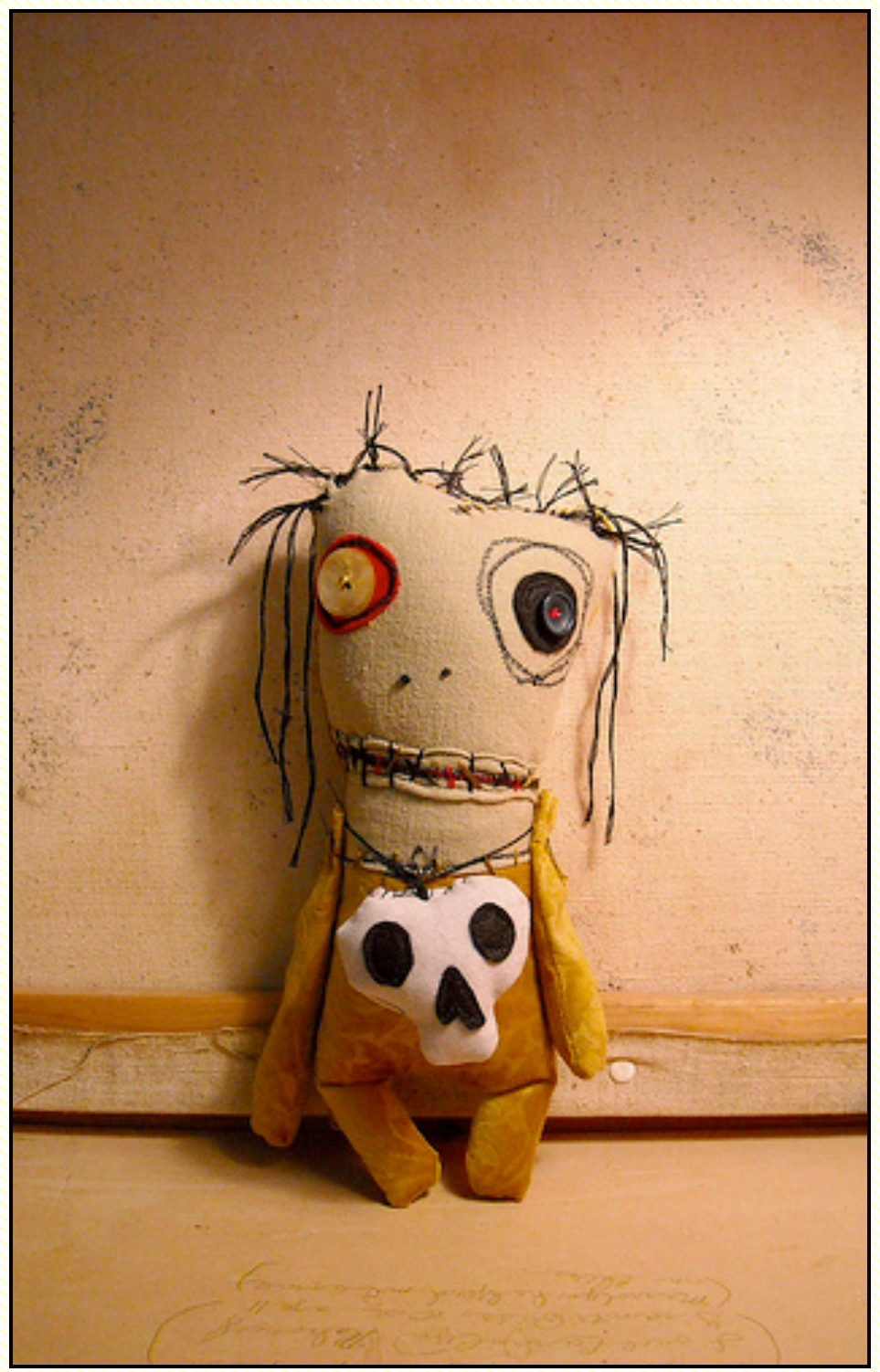

Zombie Voodoo LaRue, by junkerjane a.k.a Catherine Zacchino, September 15, 2009. Shared with permission from the author http://www.flickr.com/photos/25728104@N02/3923404223. 
Flickr member junkerjane's caption “Zombie Voodoo LaRue” reads "Entranced by rhythmic drums, Zombie Voodoo LaRue slowly left the ritual circle, never to be seen again...until now." The handcrafted stuffed animal has a skull necklace, visible tattered stitching, and mismatched button eyes. It is unequivocally cute, but it is purposely made with course stitches and misaligned components that bring an element of the disturbing into dialog with its cute and soft style. The comments on the image provide a powerful point of comparison with the discussions of_Matn's Lego vignette.

Commenter 1: so cool love the hair and skull looks like a real voodoo warrior!

Commenter 2: Dude i want you to be my stylist!!!!

Commenter 3: Wow, another absolutely rockin' creation from junkerjane. I know you probably get tired of hearing this but you rock girl. Your creativity is definitely shining and flowing!

Commenter 4: He looks dazed and confused! :) I love his skelly necklace - and that little bit of red is perfect!

Commenter 5: Way wonderful. I like his story too.

Commenter 6: Oh my,, I think he has seen better days... He is just Great!!

Commenter 7: Your insane little softies would make ANYBODY smile. XOX

Much like the comments on_Matn's Lego vignette, these comments focus on specific elements of the composition. Commenter 2 makes a broader comment on how much she enjoys the overall style of the creation. Commenter 3 connects her appreciation of the image to her admiration of junkerjane's creative ability and skill. Throughout the exchange junkerjane responds to thank the community for its feedback.

Junkerjane's Flickr profile provides additional context for understanding her creation. She notes "I have always loved junk and I have always created. I am most inspired by second hand ingredients." Further, she notes that some of her creations have been featured on the cover of Stuffed Magazine, a print publication showcasing 
handcrafted felt, crocheted, knitted, and sewed creatures frequently referred to as softies. In short, Flickr provides a space to share the dolls and animals for which she has received critical acclaim and which she also sells in her online store hosted through Etsy.

\section{Zombie Walks, Zombie Lurches, and Zombie Crawls}

The last major cluster of images in this sample set are those associated with zombie walks. Nearly $40 \%$ of the images in this collection are tagged with, or titled in reference to, a zombie walk (113/300). Of these images, about two-thirds show close-up images of individual participants' zombie costumes, while the remaining third are primarily images of large groups of costumed zombies circulating in different cities around the globe. The large group photos serve to document the zombie walks and give a sense of scale to the masses of undead lurching across different metropolitan areas. These images capture and document the fun of the zombie walk experience. They focus attention on the mass experience of the zombie horde hobbling across familiar cityscapes. The bulk of the images, however, are not focused on these wide shots of the horde, but on individual zombies, with the camera directed toward close-ups of each participant's costume.

Much like the previous examples, once again the focus of these images is on costuming and makeup. The irony lies in the fact that while the figure of the zombie in film and media is often regarded as a dehumanizing, de-individualizing force that subsumes all victims into a mindless swarm, the zombie as seen on Flickr operates in the exact opposite manner, serving as a vehicle for individual distinction, expression and commendation. For example, the image "Test Zombie Bite" shows a close-up of a hand with detailed make-up used to make it appear as if the hand has a large infected zombie bite on it. One poster writes, "AWESOME - good make-up dude!...gonna have to tell a few fellow zombie heads about this one." Other images document how participants have used make-up to make it look like they are pregnant with a zombie baby's arms bursting out of their bellies. Many of the photos 
showcase missing eyes, limbs, and jaw bones. The various states of decay possible with the zombie opens up a wide range of possibilities for costume creation.

\section{What Flickr Says About Zombies}

What is it about the zombie that makes it such a potent metaphor? Or, what is it about the zombie that has captivated our cultural imagination? It would be unwise to suggest that there is any single cause behind the various behaviors documented in these Flickr photos, but some intriguing trends emerge from this analysis such as the attention to technical mastery of a particular craft and the use of the zombie as a way of asserting individualized identity.

Rather than addressing the question of why zombies, what these examples illustrate more significantly is what these Flickr community members are doing with zombies. Whether it be Lego, costumes, make-up, cakes, or the technical artistry of the photographs themselves, the primary activity documented in the Flickr members images and reinforced in the comments is the practices associated with the production of the images. Members offer a particular object for scrutiny and their viewers comment on the particular features of its construction that appeal to them. In the case of the Lego creations, people want to know how to make the kitchen sink. These images and comments document an informally-networked, doit-yourself culture in which curious individuals share techniques and the results of their efforts at creating a wide range of handmade products. In this capacity they are not only creating and documenting these zombie artifacts and costumes, but also creating zombie narratives. The creative resourcefulness of these makers is rewarded with praise. The zombie is a kind of visual token that individuals employ in their cultural productions as part of a participatory culture gift economy. The mindlessness of the zombie is frequently examined as a representation of capitalism or excesses of consumption in society (for example see Lars Bang Larsen 2010). However, in these cases those characteristics of the zombie provide fodder for a diverse range of cultural production, which then serves as the basis for this 
participatory gift economy. The zombie provides a cultural trope to engage with, joke about, and play with. One might suggest that this tells us more about Flickr than it tells us about zombies. I would posit, however, that the growth of social spaces, like Flickr, where individuals share their compositions, is intimately connected to the popularity of the zombie. Ironically, while the zombie frequently represents a loss of individuality, the cultural trope of the zombie affords significant space to express individual creativity.

There are further reasons why the zombie has shown itself to be such a versatile concept. First, zombies provide an easy juxtaposition. It is telling that so many of the combinations discussed here involve elements associated with youth and the cute, or in the case of cakes and Lego, the domestic. If one wants to play with the values associated with something like a stuffed animal or Legos, both commonly viewed as safe and wholesome objects of childhood, then something like a zombie provides a ready-made, easily identifiable juxtaposition. This juxtapose-able notion of the zombie provides a ready means for anyone to subvert the safe, cute, and the domestic. Further, it lets one both express affinity and interest in objects from childhood or domesticity, while simultaneously distancing one's self, or complicating one's relationship, with assumptions about the kinds of people one assumes engage in the specific safe, cute, or domestic activity.

The juxtaposition that the zombie provides brings historical zombie characteristics with it. In this sense, film scholar Kyle Bishop's suggestion that one understand zombies in American culture as part of a broader gothic literary tradition offers insight into how the zombie works on Flickr. He argues that "the zombie functions primarily as a social and cultural metaphor, a creature that comments on the society that produced it by confronting audiences with fantastic narratives of excesses and extremes" (2010,31). It is exactly these fantastic and excessive characteristics that make zombies so ready to use. When these individuals invoke the zombie they infuse their creation with the history of the zombie character. 
Second, zombies make for good costumes. If you want to show off how clever you are at creating costumes, the various states of decay and missing limbs and body parts associated with zombies in mass culture make it a fun character to play with. In the case of costume design and make-up, the malleability of the idea of the zombie is attractive. Consider the next go-to undead monster, the vampire. From a costume design perspective vampires do not afford as many possibilities as zombies. A solid vampire costume can be put together with a set of fangs. In contrast, the zombie offers a wide range of bite marks, missing limbs and missing jawbones.

Third, zombies are already hip. At some point, one needs to accept the selfreinforcing element associated with all things fashionable. Part of why people are talking about and playing with zombies is simply that other people are already talking about and playing with zombies. For whatever reason, or non-reason, zombies have become a cultural trope, and that trope has created an audience. On this level, the infectious character of the zombie metaphor is primarily an artifact of the infectious nature of cultural trends.

\section{What Flickr Zombies Say About Digital Culture}

I initially framed this essay in terms of Fiske's conception of the relationship between mass culture and popular culture. These concepts provide a helpful framework for understanding how culture is used. In turn, I would like to suggest that this case provides material to refine the framework itself. At the core of Fiske's idea, popular culture is about resisting mass culture. One can think of the way Flickr community members are interacting with zombies as resistance. In this view, the Lego images show resistance to the idea of Lego as a children's toy, and the idea of an ugly-cute zombie softie similarly resists tropes about the cute and childhood. With that noted, based on the way individuals talk about and engage with these creations I would be uncomfortable with such an assertion. Instead of resisting mass culture, Flickr members are playing with it. They make jokes about it, mix it, mash it, 
and express their creativity through their play.

Beyond the creations of the Flickr community several of the examples I have cited speak to the way e-commerce is further altering distinctions between mass and popular culture. In Fiske's work the consumptive nature of consumer activity establishes resistance as a core element of popular culture. That idea of resistance breaks down in the logic of the systems and communities making use of Flickr. In the case of Lego, enthusiasts have founded small companies like The Big Toy Hut and BrickArms that provide other enthusiasts with pieces that fit their uses and desires. Beyond resistance, these individuals have become entrepreneurs. They provide their communities with the kinds of components Lego is unwilling to provide. In the case of "Zombie Voodoo LaRue," junkerjane has used Flickr and Etsy to build a following for her work and sell it directly to that community. In her case, that work has attracted enough attention to have it featured in Stuffed Magazine. Her work is now on the cover of a magazine available at major bookstores, and sewing shops around the world.

Technology writer Chris Anderson's notion of the long tail can help put these examples into a broader context (2006). Anderson proposed that the success of sites like Amazon and Netflix is tied to their ability to capitalize on markets that had previously been underserved. He suggests that the systems these two companies have in place allow them to make a large profit from selling small volumes of specialty items instead of selling large volumes of the most popular books. In effect, the structure of Amazon's site allows Amazon to sell a few copies of hundreds of thousands of books instead of selling a hundred thousand copies of a handful of books. He named this notion the long tail in reference to a graph of sales. If you graph sales of books you will generally see a handful of very popular items with considerable sales that quickly tapers off to a majority of books with limited sales. The part of the graph that tapers off is referred to as the "long tail." In this case, the increasingly decentralized structure of commerce on the web has the effect of destabilizing some of the components of the relationship between mass and popular 
culture, which I would suggest enables individuals to shift from resistance to playful production.

In 1989 when Fiske developed his approach to popular and mass culture, the dominant communications technologies much more clearly aligned with the spread of mass culture. Broadcast media like television and radio are primarily means to push messages out. Understood in this context, the notion of resistance and adaptation makes a considerable amount of sense. While it is easy to overemphasize the differences that web enabled communications technologies and platforms have brought, it is critical to note that the ability for individual members of communities to broadcast, and sell, their own ideas about culture have been dramatically increased. The idea of participatory culture provides valuable insight into some of these changes. However, the focus on commodities and commerce in Fiske's notions of popular and mass culture are still clearly salient in understanding the interactions on Flickr. The way Flickr community members are playing with the idea of the zombie tells us a considerable amount about zombies, but it also tells us a lot about complicated cultural ecology which new media is enabling.

Ultimately, I think treating these search results as a text created by a distributed vernacular authorship of people and algorithms provides us with a useful frame for critical analysis. The social interaction around these photos becomes a part of the process of their creation. The way in which individuals share these images and comment on them is inextricably linked with the way that Flickr's relevance algorithm prioritizes search results. When we expand our notion of the text to include this interplay between creators and algorithms, we can apply traditional modes of close reading to the relationships between the design of these systems and the composition of the results shown in those systems. 
has a doctorate in social science research methods and a master's degree in American history with an emphasis on digital history from George Mason University. In 2014, he won the Society for American Archivists Archival Innovator Award.

\section{References}

Anderson, Chris. 2006. The Long Tail: Why the Future of Business is Selling Less of More. New York, NY: Hyperion

Bishop, Kyle William. 2010. American Zombie Gothic: The Rise and Fall (and Rise) of the Walking Dead in Popular Culture. Jefferson, N.C: McFarland \& Co.

Collier, Malcolm. 2001. "Approaches to Analysis in Visual Anthropology.” In Handbook of Visual Analysis, ed. Theo van Leeuwen and Carey Jewitt, pp. 3561. London: Sage Publications.

de Certeau, Michel. 1984. The Practice of Everyday Life. Berkeley, CA: University of California Press.

Fiske, John. 1989. Understanding Popular Culture. London, UK: Routledge.

Howard, Robert Glenn. 2008. The Vernacular Web of Participatory Media. Critical Studies in Media Communication 25, no. 5:490.

Jenkins, Henry, Katie Clinton, Ravi Purushotma, Alice J. Robison, and Margaret Weigel. 2009. Confronting the Challenges of Participatory Culture: Media Education for the 21st Century. Cambridge, MA: The MIT Press.

Larsen, Lars Bang. 2010. Zombies of Immaterial Labor: The Modern Monster and the Death of Death. e-flux journal 15(5). http://e-flux.com/journal/zombies-ofimmaterial-labor-the-modern-monster-and-the-death-of-death/.

Manovich, Lev. 2001. The Language of New Media. Cambridge, Mass: MIT Press. 